\title{
Atmospheric deposition of nitrogen to the Baltic Sea in the period 1995-2006
}

\author{
J. Bartnicki, V. S. Semeena, and H. Fagerli \\ Research and Development Department, Norwegian Meteorological Institute, Oslo, Norway \\ Received: 15 December 2010 - Published in Atmos. Chem. Phys. Discuss.: 19 January 2011 \\ Revised: 6 June 2011 - Accepted: 13 September 2011 - Published: 4 October 2011
}

\begin{abstract}
The EMEP/MSC-W model has been used to compute atmospheric nitrogen deposition into the Baltic Sea basin for the period of $12 \mathrm{yr}$ : 1995-2006. The level of annual total nitrogen deposition into the Baltic Sea basin has changed from $230 \mathrm{Gg} \mathrm{N}$ in 1995 to $199 \mathrm{Gg} \mathrm{N}$ in 2006, decreasing $13 \%$. This value corresponds well with the total nitrogen emission reduction (11\%) in the HELCOM Contracting Parties. However, inter-annual variability of nitrogen deposition to the Baltic Sea basin is relatively large, ranging from $-13 \%$ to $+17 \%$ of the averaged value. It is mainly caused by the changing meteorological conditions and especially precipitation in the considered period. The calculated monthly deposition pattern is similar for most of the years showing maxima in the autumn months October and November. The source allocation budget for atmospheric nitrogen deposition to the Baltic Sea basin was calculated for each year of the period 1997-2006. The main emission sources contributing to total nitrogen deposition are: Germany $18-22 \%$, Poland $11-13 \%$ and Denmark 8-11\%. There is also a significant contribution from distant sources like the United Kingdom 6-9\%, as well as from the international ship traffic on the Baltic Sea 4-5\%.
\end{abstract}

\section{Introduction}

The effects of eutrophication are most likely the single greatest threat to the unique and fragile environment of the Baltic Sea (HELCOM, 2010). Nitrogen and phosphorus are the main nutrients which in high concentrations stimulate growth of algae which in turn leads to imbalanced functioning of the

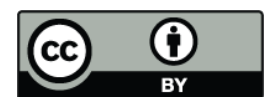

Correspondence to: J. Bartnicki

(jerzy.bartnicki@met.no) system and eutrophication (HELCOM, 2009). The nitrogen input entering the Baltic Sea is both airborne and waterborne, whereas phosphorus input is mostly waterborne (HELCOM, 2010). Atmospheric deposition of nitrogen accounts for approximately one quarter to one third of the total nitrogen input to the Baltic Sea (HELCOM, 2005a) and has been regularly monitored by following the results of measurements and model calculations.

The Co-operative Program for Monitoring and Evaluation of the Long-Range Transmission of Air Pollutants in Europe (EMEP) and the Baltic Marine Environment Protection Commission (HELCOM) are both conducting work on air monitoring, modelling and compilation of emission inventories of different pollutants, especially nitrogen species. In 1995, HELCOM decided to rationalize its current programs by avoiding duplication of efforts with specialised international organizations. At the request of HELCOM, the steering Body of EMEP at its nineteenth session agreed to assume the management of atmospheric monitoring data, the preparation of air emission inventories and the modelling of air pollution in the Baltic region.

Following this agreement, the EMEP Centres have been responsible for regular evaluation of the state of the atmosphere in the Baltic Sea region and have produced the annual joint summary reports with updated emissions of nitrogen compounds, heavy metals and POPs, modelled deposition fields, allocation budgets and measurement data. Altogether thirteen joint EMEP Centres reports for HELCOM have been published, the last one in 2010 (Bartnicki et. al., 2010).

The contribution of airborne to total (airborne + waterborne) nitrogen input into the Baltic Sea basin varies significantly from one year to another. We have calculated the airborne contribution for each year of the period 1995-2006 based on the results of EMEP Unified model presented here

Published by Copernicus Publications on behalf of the European Geosciences Union. 


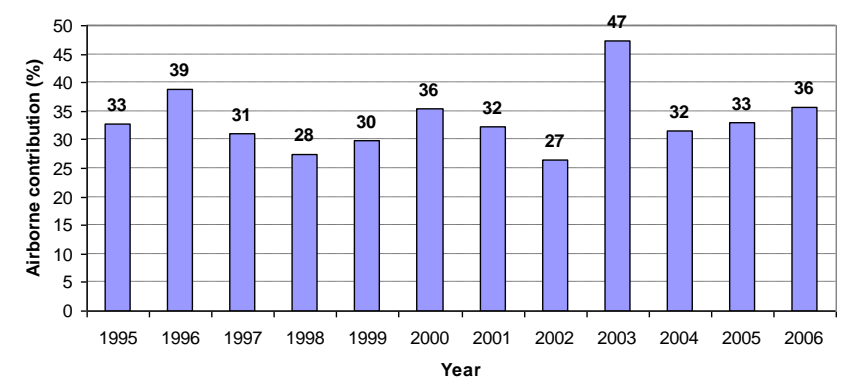

Fig. 1. Annual airborne contribution to total (waterborne plus airborne) input of nitrogen into the Baltic Sea basin in the period 1995-2006. Units: \% of total input.

and the information about waterborne input into the Baltic available in Wulff et al. (2006). Typically, the airborne contribution is a quarter to one third of the total input. However, the results in Fig. 1 show a large inter-annual variation in airborne contribution to nitrogen input, with minimum $-27 \%$ in the year 2002 and maximum $-47 \%$ in the year 2000, significantly exceeding the typical range. In the year 2000 dry and wet deposition of nitrogen from the air is reaching maximum for the entire period, whereas the waterborne input is at the minimum. The maximum of airborne contribution reaching almost $50 \%$ in the year 2000 indicates that the estimation of atmospheric nitrogen deposition is important for the accurate calculation of total nitrogen input into the Baltic Sea.

The estimation of airborne nitrogen input to the Baltic Sea is based on both measurements (Rolf et al., 2008; HELCOM, 2005a) and on modelling studies (Hertel et al., 2003; Langer et al., 2009; Bartnicki et al., 2010). Rolf et al. (2008) noticed a deposition gradient from the coastal regions to open waters or remote islands. Langner et al. (2009) estimated the present and future deposition of nitrogen into the Baltic Sea using the Eulerian chemical transport model MATCH. The calculated average total nitrogen deposition in the period 1992-2001 was in the range $261-300 \mathrm{Gg} \mathrm{N} \mathrm{yr}^{-1}$ with interannual variability $5.1-8.0 \%$. Their study predicts around $5 \%$ increase in the total deposition of reactive nitrogen into the Baltic Sea towards the end of 21st century. Hertel et al. (2003) calculated the annual 1999 deposition of nitrogen into the Baltic Sea with the ACDEP model. The calculated annual deposition was equal to $318 \mathrm{Gg} \mathrm{N} \mathrm{yr}^{-1}$ for the basin area $464406 \mathrm{~km}^{2}$. The deposition showed maximum over Danish waters during the mid summer periods when the algal growth is high whereas the deposition maximum values were distributed over most of the year in the northern part of the Baltic Sea. On the other hand, long-term trends in nitrogen deposition are generally related to the trends in anthropogenic emissions, meteorological variability, nonlinearities in atmospheric chemistry and these factors can offset the expected changes in deposition.

Here we present and discuss the most important results of the EMEP work for HELCOM concerning atmospheric ni-

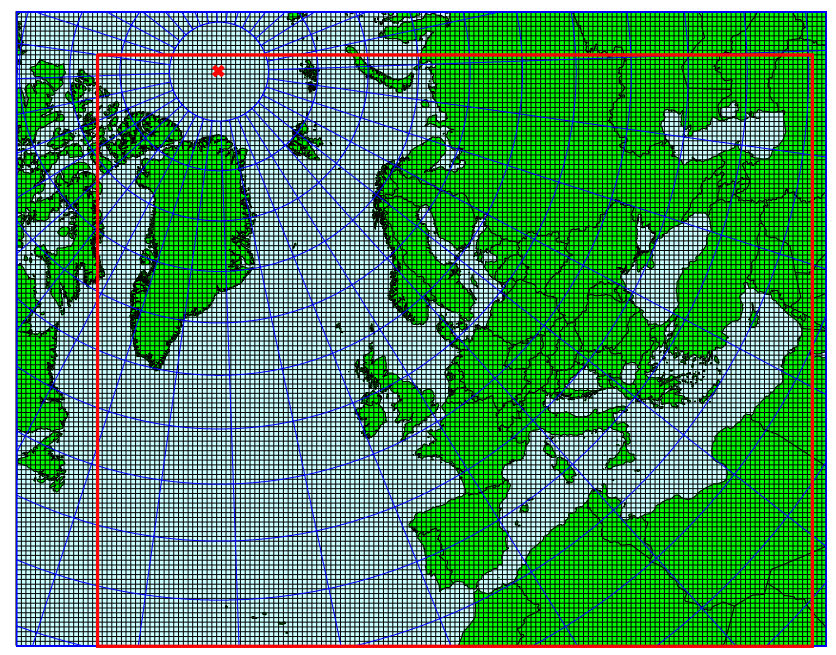

Fig. 2. Standard computational domain of the EMEP Unified model (external frame) and reduced domain (internal red frame) where computations of nitrogen deposition were performed for the period 1995-2006.

trogen deposition to the Baltic Sea. We have chosen the period 1995-2006 for the calculation of nitrogen deposition for several reasons. Firstly, because the consistent and continuous meteorological and emission data are available for the selected time frame only. Secondly, we could use for the entire period, exactly the same version (rv3.1) of the EMEP Unified model as well as the same computational model domain. Under normal operation, the EMEP model is frequently improved and changed, almost every year and often different model versions are applied for calculating transport and deposition in different years. The same applies to meteorological data, which can be provided by different Numerical Weather Prediction (NWP) models in different years. By selecting the 1995-2006 period, we managed to avoid these kind of problems in the present study.

The standard computational domain of the EMEP model is shown in Fig. 2 together with slightly smaller domain which was used for calculations presented here. The size of the standard model grid is $170 \times 133$ nodes and its resolution is $50 \mathrm{~km}$ in Polar Stereographic Projection at $60^{\circ} \mathrm{N}$. The Baltic Sea Basin is located in the centre of the reduced model domain, which is large enough for the estimation of nitrogen deposition and source receptor allocation for the Baltic Sea basin.

All meteorological input data, including precipitation, necessary to run the EMEP model in the considered period were provided by the PARLAM NWP model (Bjørge and Skålin, 1995; Benedictow, 2003) developed at met.no. The PARLAM model is a special version of the HIRLAM NWP model (Undén et al., 2002). 

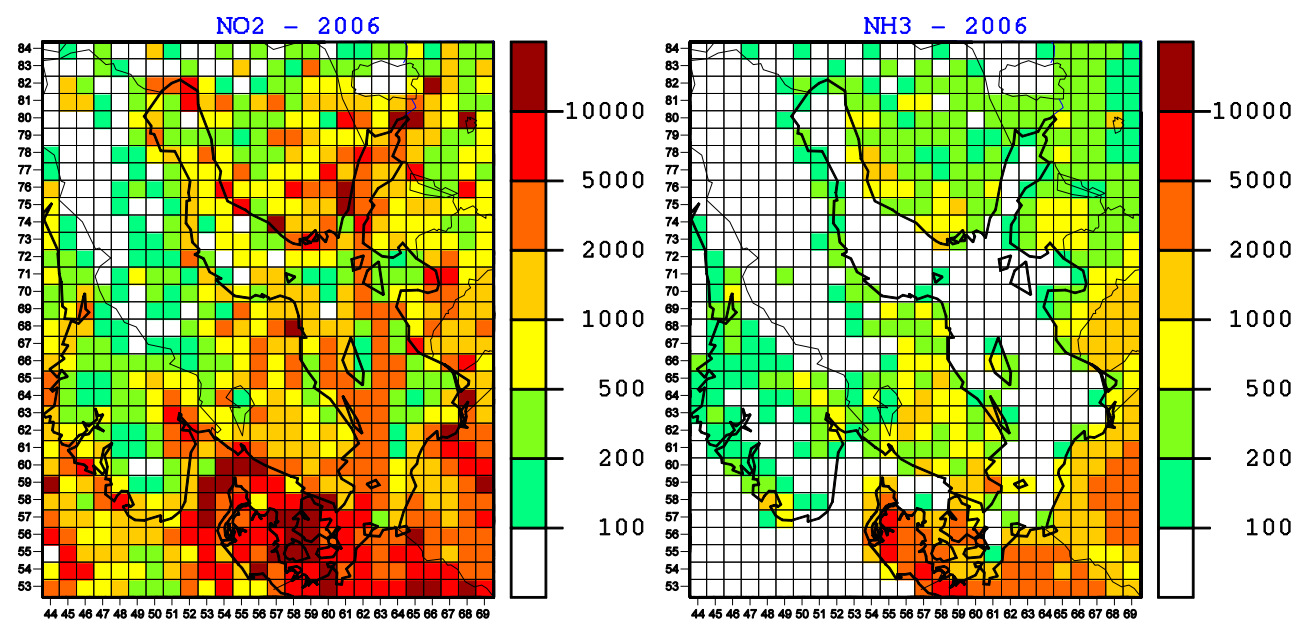

Fig. 3. Spatial distribution of annual 2006 nitrogen dioxide emissions (left) and annual 2006 ammonia emissions (right) in the model grid covering the Baltic Sea region. Units: $\mathrm{MgN}$ per year and per grid.

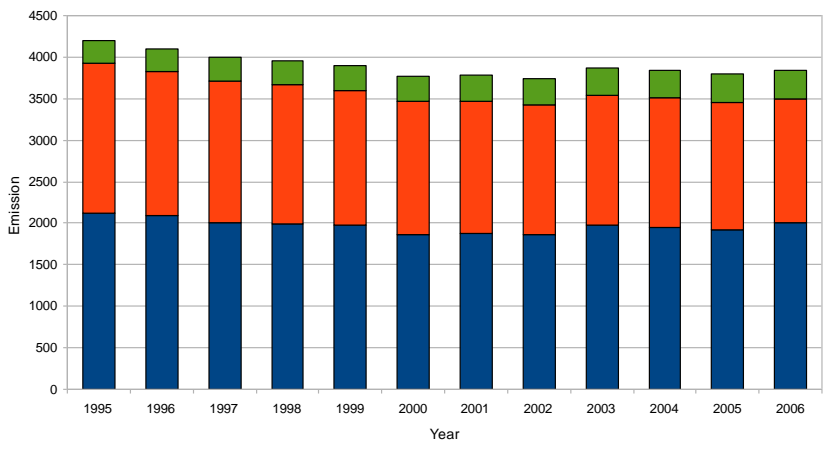

Fig. 4. Annual emissions of nitrogen oxides $\left(\mathrm{NO}_{2}-\mathrm{N}\right)$ and ammonia (NH3-N) from all HELCOM Contracting Parties and annual nitrogen oxides emissions from the international ship traffic on the Baltic Sea (BAS-N) in the period 1995-2006. Units: Gg N per year.

\section{Nitrogen emissions}

As far as possible, the emission data submitted by the EMEP Contracting Parties have been used in the model runs presented in this study. However, in case of missing or incorrect data, the expert estimates were used instead (Vestreng, 2003). Annual total emissions of sulphur dioxide $\left(\mathrm{SO}_{2}\right)$, nitrogen oxides $\left(\mathrm{NO}_{\mathrm{x}}=\mathrm{NO}+\mathrm{NO}_{2}\right)$, ammonia $\left(\mathrm{NH}_{3}\right)$, non-methane volatile organic compounds (NMVOC), carbon monoxide $(\mathrm{CO})$, and particulates $\left(\mathrm{PM}_{2.5}, \mathrm{PM}_{10}\right)$ are submitted every year, by each Contracting Party. In addition, spatial distributions of these emissions in the EMEP grid system are being updated approximately once in five years, since the locations of main sources in each country do not change very often. For the modelling purpose the submitted emission data, as well as the emission data from international ship traffic are verified and eventually corrected by experts. The description of procedures used for collecting anthropogenic emissions, filling-in gaps, and for spatial distribution can be found in (Vestreng, 2003; EMEP, 2010). The emission data used in this study for the period 1995-2005 have been originally compiled at the meteorological Synthesizing CentreWest (MSC-W) in Oslo and that for the year 2006 have been compiled at the Centre for Emission Inventories and Projections (CEIP) located in the Federal Environment Agency in Vienna, Austria and can be found on the CEIP's web pages (CEIP, 2010). For the final model runs, the latest emissions available at MSC-W in 2010 have been used (Semeena et al., 2009).

Emissions of different kinds of pollutants can influence the amount of nitrogen deposition to the Baltic Sea, however, emissions of nitrogen oxides and ammonia are the major and dominating contributors to nitrogen deposition. Transportation and combustion are the main activities producing nitrogen oxides emissions, whereas agriculture is a dominating source for ammonia emissions. Emissions from the HELCOM Contracting Parties and international ship traffic on the Baltic Sea are especially important for nitrogen deposition into the Baltic Sea, because together they contribute more than $50 \%$ of total $\mathrm{N}$ deposition. Time series of annual emissions of nitrogen oxides and ammonia for the HELCOM Contracting Parties in the period 1995-2006 are shown in Tables 1 and 2. In most of the HELCOM countries nitrogen oxide emissions are decreasing in the considered period with largest reductions in Sweden and Germany, both by $35 \%$. In two countries nitrogen oxides emissions are higher in 2006 than in 1995. These are Russia (30\%) and Latvia (7\%), with the increasing trend beginning already in the year 2000. Also ammonia emissions have reduced in the period 1995-2006, in most of the HELCOM Contracting Parties with the largest reductions in Russia (28\%) and Poland (25\%). In two HELCOM countries ammonia emissions are slightly higher in 2006 than in 1995: in Finland (4\%) and in Lithuania (3\%). 


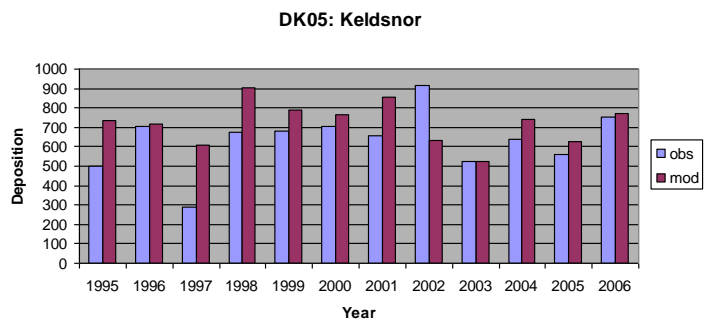

EE11: Vilsandi

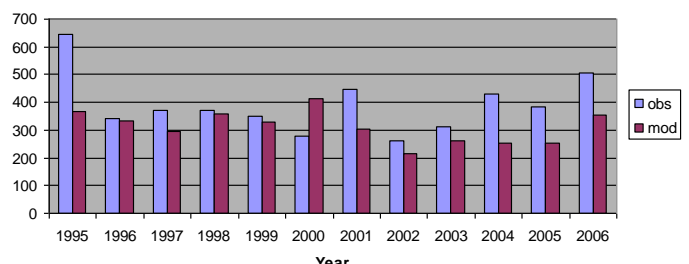

Year

F109: Utö

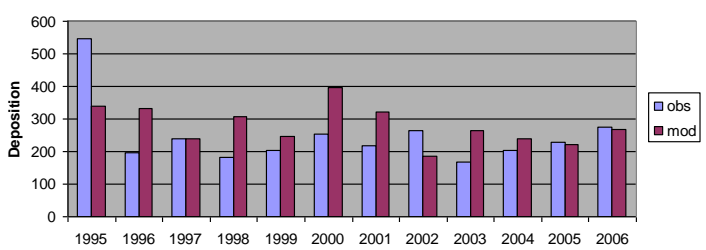

LT15: Preila

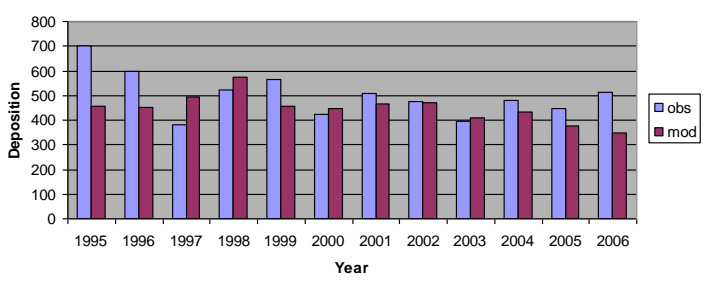

PL04: Leba

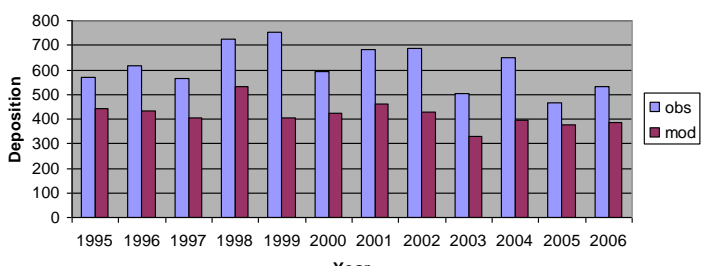

Year

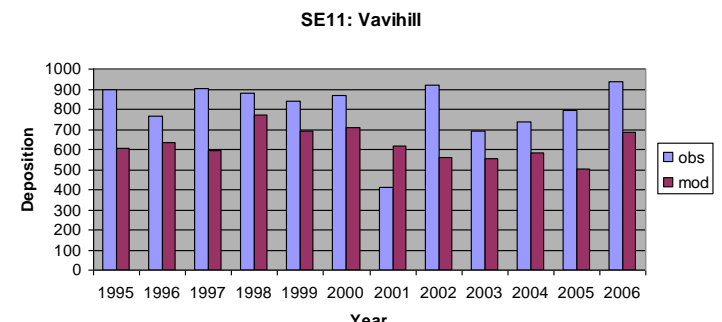

Year

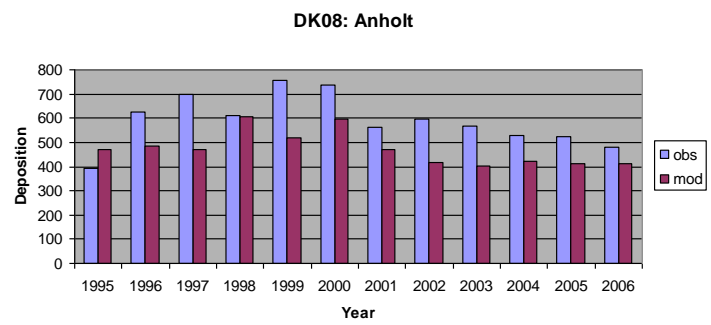

F104: Ähtäri

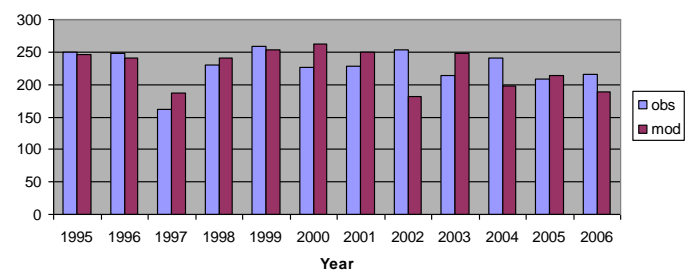

Fl17: Virolahti II

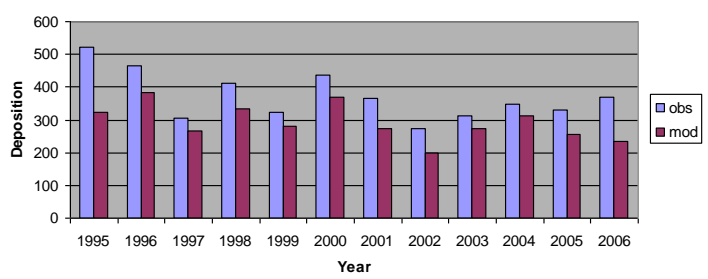

LV10: Rucava

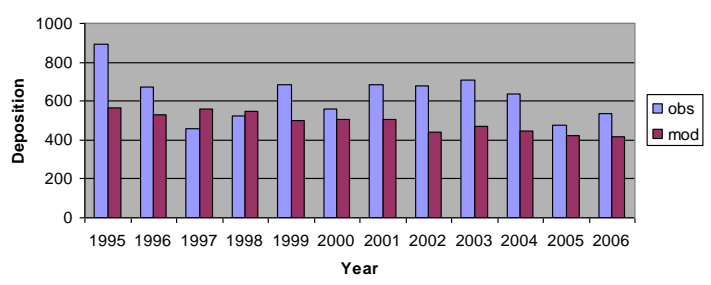

SE05: Bredkälen

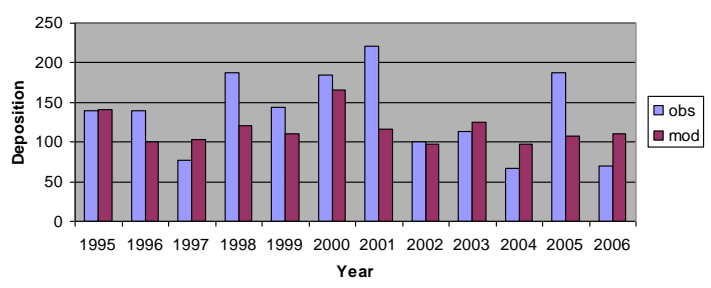

Annual precipitation

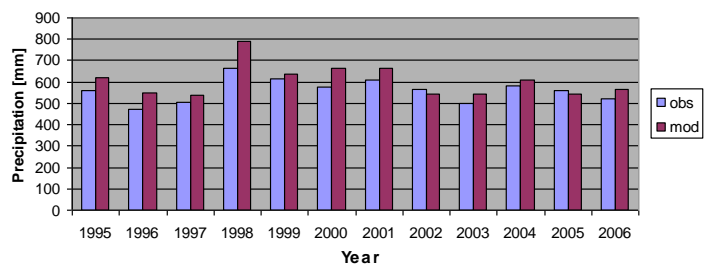

Fig. 5. Comparison of annual wet deposition based on observations (obs) at selected HELCOM stations and calculated by the EMEP model (mod) for the grid squares including these stations, for each year of the period 1995-2006. Units: $\mathrm{mg} \mathrm{N} \mathrm{m}^{-2}$. Annual precipitation to the Baltic Sea basin is also compared as average from measurements over 11 stations (obs) and average over all model grids covering Baltic Sea basin (mod). 
Table 1. Annual emissions of nitrogen oxides in HELCOM Contracting Parties and from the international ship traffic on the Baltic Sea in the period 1995-2006. Units: $\mathrm{Gg} \mathrm{NO}_{2}$ per year.

\begin{tabular}{ccccccccccc}
\hline \multirow{2}{*}{ Year } & & \multicolumn{9}{c}{ HELCOM Contracting Party } \\
& Denmark & Estonia & Finland & Germany & Latvia & Lithuania & Poland & Russia & Sweden & Baltic \\
\hline 1995 & 252.7 & 38.5 & 258.0 & 2131.1 & 40.9 & 64.6 & 1121.0 & 2788.4 & 270.5 & 267.5 \\
1996 & 290.0 & 41.4 & 268.1 & 2050.3 & 42.6 & 64.2 & 1155.0 & 2688.1 & 260.7 & 274.3 \\
1997 & 244.2 & 40.2 & 258.9 & 1975.6 & 40.9 & 63.4 & 1114.0 & 2628.9 & 249.8 & 281.2 \\
1998 & 221.2 & 38.9 & 251.1 & 1939.5 & 38.7 & 65.4 & 991.0 & 2758.5 & 241.8 & 288.3 \\
1999 & 205.4 & 34.5 & 247.0 & 1915.7 & 36.6 & 57.4 & 953.0 & 2795.9 & 230.1 & 295.5 \\
2000 & 187.6 & 36.7 & 235.3 & 1854.7 & 34.4 & 48.7 & 838.0 & 2666.3 & 217.1 & 303.0 \\
2001 & 183.7 & 37.7 & 219.7 & 1762.8 & 37.9 & 47.0 & 847.9 & 2801.2 & 210.8 & 310.6 \\
2002 & 180.8 & 40.1 & 207.6 & 1674.1 & 36.8 & 51.3 & 796.0 & 2927.5 & 205.5 & 318.5 \\
2003 & 189.0 & 39.2 & 217.6 & 1604.7 & 38.2 & 52.6 & 808.1 & 3368.8 & 202.7 & 326.5 \\
2004 & 171.4 & 36.8 & 204.7 & 1554.3 & 38.8 & 54.7 & 804.2 & 3356.2 & 197.4 & 334.7 \\
2005 & 185.8 & 32.1 & 177.4 & 1443.1 & 41.1 & 57.6 & 810.9 & 3356.2 & 204.9 & 343.2 \\
2006 & 185.3 & 30.5 & 192.8 & 1394.3 & 43.8 & 61.4 & 889.6 & 3634.9 & 174.6 & 346.7 \\
\hline
\end{tabular}

Table 2. Annual emissions of ammonia in HELCOM Contracting Parties in the period 1995 - 2006. Units: Gg NH 3 per year.

\begin{tabular}{cccccccccc}
\hline Year & & \multicolumn{9}{c}{ HELCOM Contracting Party } & & \\
& Denmark & Estonia & Finland & Germany & Latvia & Lithuania & Poland & Russia & Sweden \\
\hline 1995 & 113.8 & 12.1 & 34.8 & 642.1 & 15.1 & 34.1 & 378.0 & 908.1 & 63.8 \\
1996 & 109.9 & 11.0 & 36.2 & 645.3 & 14.3 & 36.1 & 363.0 & 826.8 & 61.3 \\
1997 & 109.6 & 11.2 & 37.6 & 636.5 & 14.1 & 38.1 & 349.0 & 806.2 & 61.7 \\
1998 & 111.0 & 11.1 & 35.4 & 643.6 & 13.2 & 39.7 & 369.0 & 746.5 & 61.0 \\
1999 & 105.9 & 9.6 & 33.1 & 649.6 & 12.0 & 41.5 & 340.0 & 727.0 & 58.8 \\
2000 & 105.4 & 8.8 & 33.0 & 645.9 & 12.1 & 43.5 & 321.0 & 719.4 & 58.2 \\
2001 & 104.5 & 9.0 & 33.2 & 659.4 & 13.6 & 44.7 & 328.4 & 692.2 & 56.6 \\
2002 & 101.7 & 9.1 & 33.3 & 649.3 & 13.5 & 46.1 & 325.0 & 665.1 & 56.8 \\
2003 & 97.7 & 9.6 & 33.2 & 648.3 & 14.2 & 47.4 & 322.6 & 665.1 & 56.0 \\
2004 & 97.8 & 9.7 & 33.3 & 640.7 & 13.2 & 48.7 & 316.5 & 673.8 & 56.4 \\
2005 & 92.5 & 9.3 & 36.2 & 619.4 & 13.9 & 39.4 & 326.5 & 673.8 & 52.4 \\
2006 & 89.5 & 9.3 & 36.4 & 620.8 & 14.6 & 35.0 & 286.8 & 653.2 & 52.0 \\
\hline
\end{tabular}

The maps with spatial distributions of nitrogen oxides and ammonia emissions around the Baltic Sea look similar for all the years of the considered period. As an example, the maps with spatial distributions of the annual 2006 nitrogen oxides and ammonia emissions in the Baltic Sea region are presented in Fig. 3. Nitrogen oxides emissions from the international ship traffic on the Baltic Sea are visible in the Baltic Sea basin. Emission sources of ammonia are located on the land only and they are not present in the Baltic Sea basin. There is a south-north gradient in both, nitrogen oxides and ammonia emissions, but slightly steeper for ammonia emissions.

Total HELCOM emissions calculated as a sum of contributions from the HELCOM contracting parties have been reduced during the considered period by $5 \%$ and $18 \%$, for nitrogen oxides and ammonia, respectively (Fig. 4). However, the reduction pattern was quite different for nitrogen oxides and ammonia. Nitrogen oxides emissions decreased almost linearly from 1995 to 2000 and then increased with some oscillations from 2002 to 2006 . On the other hand, a steady decrease in ammonia emissions can be observed for the entire period. The ship emissions have increased by $34 \%$ in the same period in a linear pattern with assumed $2.5 \%$ increase per year. The total (nitrogen oxides + ammonia) nitrogen emissions from the HELCOM Contracting Parties have decreased by $11 \%$ and sum of HELCOM and ship emissions has decreased by $10 \%$ in the considered period. For all the years, nitrogen oxides emissions for HELCOM sources are slightly higher (4-7\%) than ammonia emissions in nitrogen units. One of the questions which can be answered by the results of the model runs is if the main features of nitrogen emissions are reflected in the calculated nitrogen deposition or not. After 2006, in the years 2007 and 2008, both nitrogen oxides and ammonia emissions, as a sum from all HELCOM Contracting Parties and ship traffic, remain on the same level as in 2006, within $1 \%$ accuracy (CEIP, 2010). 

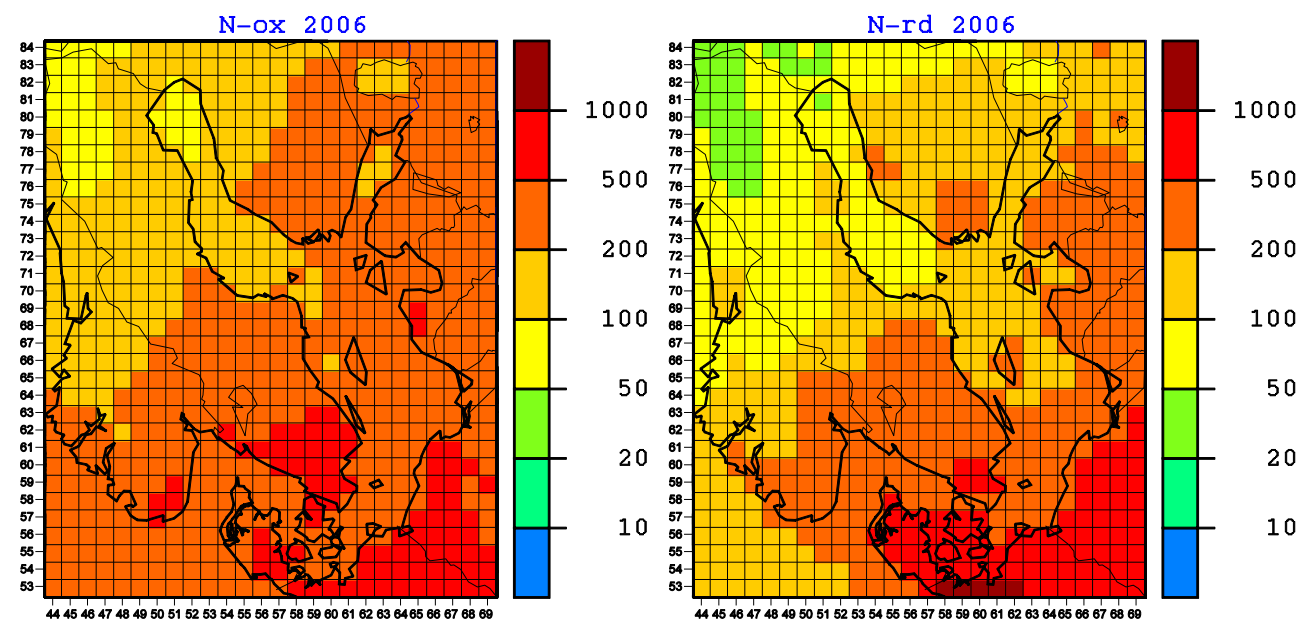

Fig. 6. Map of annual 2006 oxidised nitrogen deposition (left) and annual 2006 reduced nitrogen deposition (right). Units: $\mathrm{mg} \mathrm{N} \mathrm{m}^{-2}$.

\section{Nitrogen deposition into the Baltic Sea}

Nitrogen emission inventories described in the previous section have been used to calculate annual and monthly nitrogen deposition for the entire period of 1995-2006. The version rv3.1 of the EMEP Unified model has been used to calculate both annual and monthly deposition fields of oxidised dry, oxidised wet, reduced dry and reduced wet nitrogen to the Baltic Sea basin.

\subsection{Comparison of modelled and measured deposition}

Since the beginning of its operational application, the EMEP model has been systematically evaluated every year on the latest available measurement data and the results are published in the annual EMEP reports (Berge et al., 2010; Fagerli et al., 2011). In addition, the model evaluation has been a subject of several publications (e.g. Simpson et al., 2006a, 2006b; Fagerli and Aas, 2008). The study of Fagerli and Aas (2008) focused on comparison of modelled and measured nitrogen in air and precipitation in the long term period 1980-2003. Altogether 33 EMEP sites located in different parts of Europe were used in the study which indicated a decline of ammonium and nitrate in precipitation both in measurements and model results. However, out of 33, only 5 sites reported concentration in precipitation in the locations close to the Baltic Sea basin. Therefore, here we have used additional data from the Norwegian Institute of Air Research (W. Aas, personal communication, 2010) with measured nitrogen concentrations in precipitation and precipitation amount at so called HELCOM stations. The HELCOM stations are in fact the EMEP stations reporting in slightly different way for the HELCOM purpose. We have examined 21 HELCOM sites, of which 11 reported annual nitrogen concentrations in precipitation and precipitation amount for the entire period 1995-2006. We have used these 11 sta- tions for comparing annual wet deposition based on observations with the modelled wet deposition. In addition, annual precipitation amount to the Baltic Sea basin has been also compared as average from measurements over 11 stations and average over all model grids covering Baltic Sea basin. This comparison is shown in Fig. 5. For all stations there is a relatively good agreement between averaged observed and modelled deposition values over the entire period, but the correlation is not so good, mainly because of differences in modelled and observed precipitation amount for individual stations (not shown). This good agreement indicates that the most likely, additional reason for the differences in nitrogen deposition to the Baltic Sea basin calculated by the EMEP model and by the MATCH and ACDP models is related to different emission inventories used for the calculations. Both nitrogen and sulphur emissions were slightly lower in the EMEP calculations after latest revisions in 2010. However, different meteorology still remains an important factor for the differences.

The inter-annual variation of measured annual nitrogen deposition is similar, but larger than the inter-annual variation of modelled deposition. However, correlation between annual measured and modelled values is not very good, typically around 0.3 and this is a follow up of a bad correlation between measured and modelled annual precipitation. The modelled precipitation comes from the numerical weather prediction model and represents the entire grid square, whereas the realistic variation of precipitation within one grid square is high. In some cases it can be higher than $100 \%$ (e.g. model grid square which includes Bergen in Norway). When the model wet deposition is calculated with precipitation from the station, the correlation between measured and modelled deposition is much better, above 0.8 . 


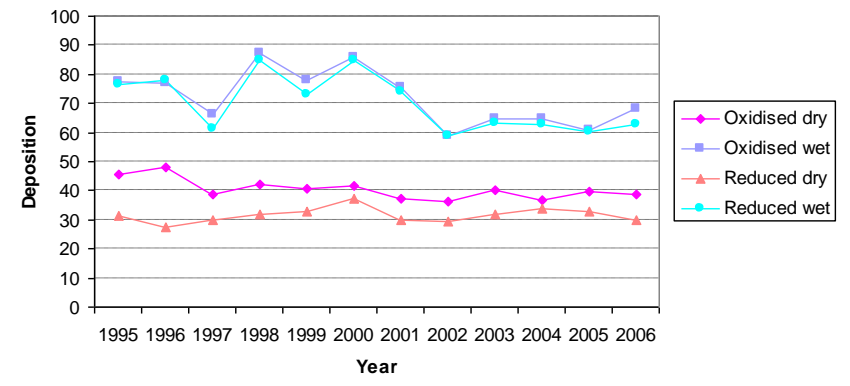

Fig. 7. Calculated annual deposition to the Baltic Sea basin of: oxidized dry, oxidised wet, reduced dry and reduced wet nitrogen in the period 1995-2006. Units: Gg N per year.

\subsection{Modelled annual deposition}

The calculated annual oxidised and reduced nitrogen deposition fields for the year 2006 are shown in Fig. 6. The spatial distribution patterns of these deposition fields are similar for all years of the considered period and therefore we present only examples for the year 2006. A clear south-north gradient can be noticed for both fields, however the gradient appears more steep for reduced nitrogen deposition. The ranges of annual 2006 deposition to the Baltic Sea basin are: 82-666 $\mathrm{mg} \mathrm{N} \mathrm{m}^{-2} \mathrm{yr}^{-1}$ and $49-1334 \mathrm{mg} \mathrm{N} \mathrm{m}^{-2} \mathrm{yr}^{-1}$, for oxidised and reduced nitrogen, respectively. Maxima of the deposition are located close to the German coastal line, whereas minima are located in the Northern part of the Baltic Sea.

Time series of oxidised dry, oxidised wet, reduced dry and reduced wet deposition to the Baltic Sea basin in the period 1995-2006 are presented in Fig. 7. For all years of the considered period, wet deposition of nitrogen is larger than dry deposition, accounting for $63-70 \%$ of total deposition. The patterns and values of oxidised wet and reduced wet deposition are very similar and remain close to each other. Contributions of oxidised dry and reduced dry deposition to total deposition are lower, with total dry deposition accounting for $30-37 \%$ of total nitrogen deposition in the considered period. There is also slightly (2-8\%) more oxidised than reduced deposition for all the years. The level of annual total nitrogen deposition into the Baltic Sea basin has changed from $230 \mathrm{Gg}$ in 1995 to $199 \mathrm{Gg}$ in 2006. Maximum of total nitrogen deposition in the considered period can be noticed in the year $2000(250 \mathrm{Gg} \mathrm{N})$, whereas minimum can be seen in the year $2002(184 \mathrm{Gg} \mathrm{N})$. All types of computed deposition are lower in the year 2006 than in the year 1995 with total nitrogen deposition decreasing $13 \%$ in 2006. This value corresponds well with the total nitrogen emission reduction $(11 \%)$ in the same period, in the HELCOM Contracting Parties.

The examination of data behind Fig. 7 shows that the reduction in modelled wet deposition in the period 20012006 compared to period $1995-2000$ is $13 \%$. Similar reduction is present in the measured deposition for the stations

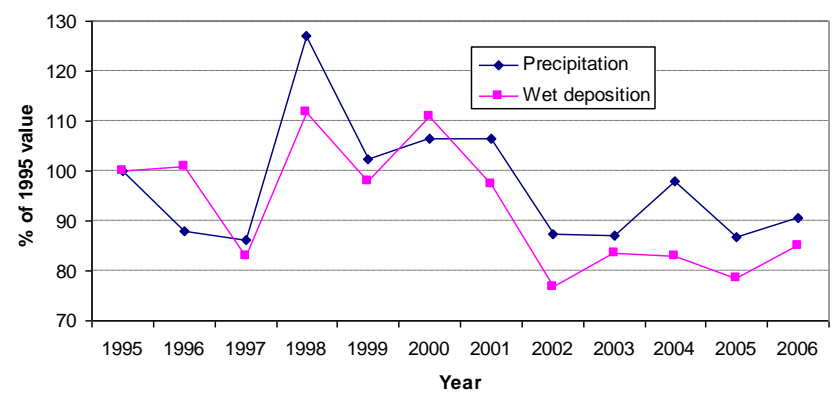

Fig. 8. Comparison of relative annual wet deposition and relative annual precipitation in the period 1995-2006. Units: Percent of 1995 annual value.

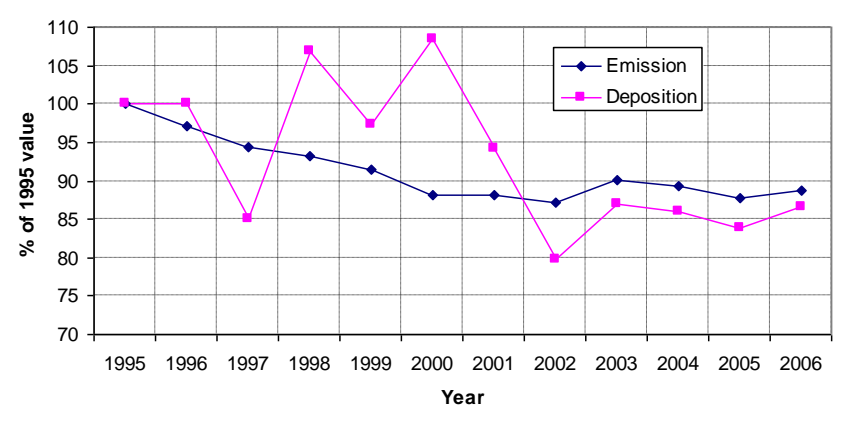

Fig. 9. Comparison of relative annual deposition of total nitrogen into the Baltic Sea basin and relative annual emissions of total (nitrogen oxides + ammonia) nitrogen from the HELCOM Contracting Parties in the period 1995-2006. Units: percent of 1995 value.

in Fig. 5. Except for two stations DK05-Keldsnor and PL04Leba, there is a clear reduction for measured wet deposition in the period 2001-2006 - on average $10 \%$. This value is quite similar and only slightly lower than predicted by the model calculations.

The temporal patterns of dry deposition in Fig. 7 are relatively smooth compared to the patterns of wet deposition, which show large inter-annual variations, especially in the period 1996-2003. Since the temporal patterns of nitrogen emissions are also relatively smooth, large variations in the wet deposition are mainly caused by variable meteorological conditions and especially precipitation. The influence of precipitation on the wet deposition pattern is clearly visible in Fig. 8 where time series of relative annual precipitation and wet deposition are compared. Figure 8 also suggests a good correlation between precipitation and wet deposition. This is confirmed by high values of correlation coefficients between precipitation and oxidised wet deposition $(0.80)$ and between precipitation and reduced wet deposition (0.76). On the other hand, smooth pattern of dry deposition suggests a good correlation between nitrogen emissions and dry deposition. This is true for nitrogen oxides emissions and deposition of oxidised nitrogen. The correlation coefficient between annual emissions of nitrogen 


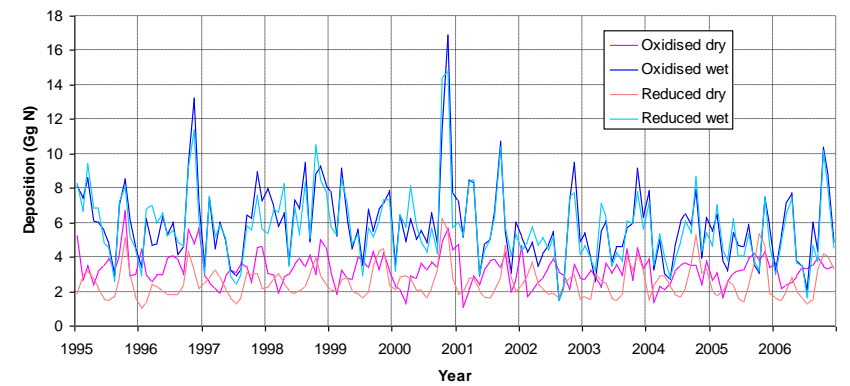

Fig. 10. Monthly deposition of oxidised dry, oxidised wet, reduced dry and reduced wet nitrogen to the Baltic Sea basin in the period 1995-2006.

oxides and annual deposition of oxidised nitrogen in the period $1995-2006$ is equal to 0.70 . These results indicate that the inter-annual variation of dry deposition is mainly forced by the changes in nitrogen emissions, whereas meteorology and mainly precipitation are responsible for inter-annual variation of wet deposition.

Comparison of relative annual total nitrogen emissions in HELCOM Contracting Parties and annual total nitrogen deposition is shown in Fig. 9. In this Figure, annual total nitrogen emission is the sum of nitrogen dioxide and ammonia emissions and relative mean percent of annual 1995 values. Emission pattern in Fig. 9 is relatively smooth, whereas large differences can be noticed in annual deposition especially in the period 1996-2002 with a sudden drop (28\%) between the years 2000 and 2002 . This sudden drop is mostly caused by the drop in modelled precipitation from years 2001 to 2002. Similar drop (18\%), but from year 2001 to 2003 is also visible in the measured precipitation data shown in Fig. 5. Figure 9, as well as Fig. 6 and 7 prove again that inter-annual variation of meteorological conditions and especially precipitation has a strong influence on annual deposition of nitrogen. One important implication from the decision point of view is the possibility of increased deposition of nitrogen after the reduction of nitrogen emission. For example, total nitrogen emission shown in Fig. 9 decreased $1.7 \%$ between 1997 and 1998, whereas total nitrogen deposition increased $25 \%$ from 1997 to 1998 (both in \% of 1995 value). Therefore, in order to evaluate and see the effects of nitrogen emission reduction, it is necessary to use a longer period than one or two years. Figure 9 indicates that the evaluation period should not be shorter than five years.

\subsection{Monthly deposition}

Calculated monthly deposition of oxidised dry, oxidised wet, reduced dry and reduced wet nitrogen to the Baltic Sea basin in the period 1995-2006 are shown in Fig. 10. As in the case of annual deposition, monthly wet deposition of oxidised and reduced nitrogen is also higher than corresponding dry deposition. In addition, patterns of monthly oxidised wet
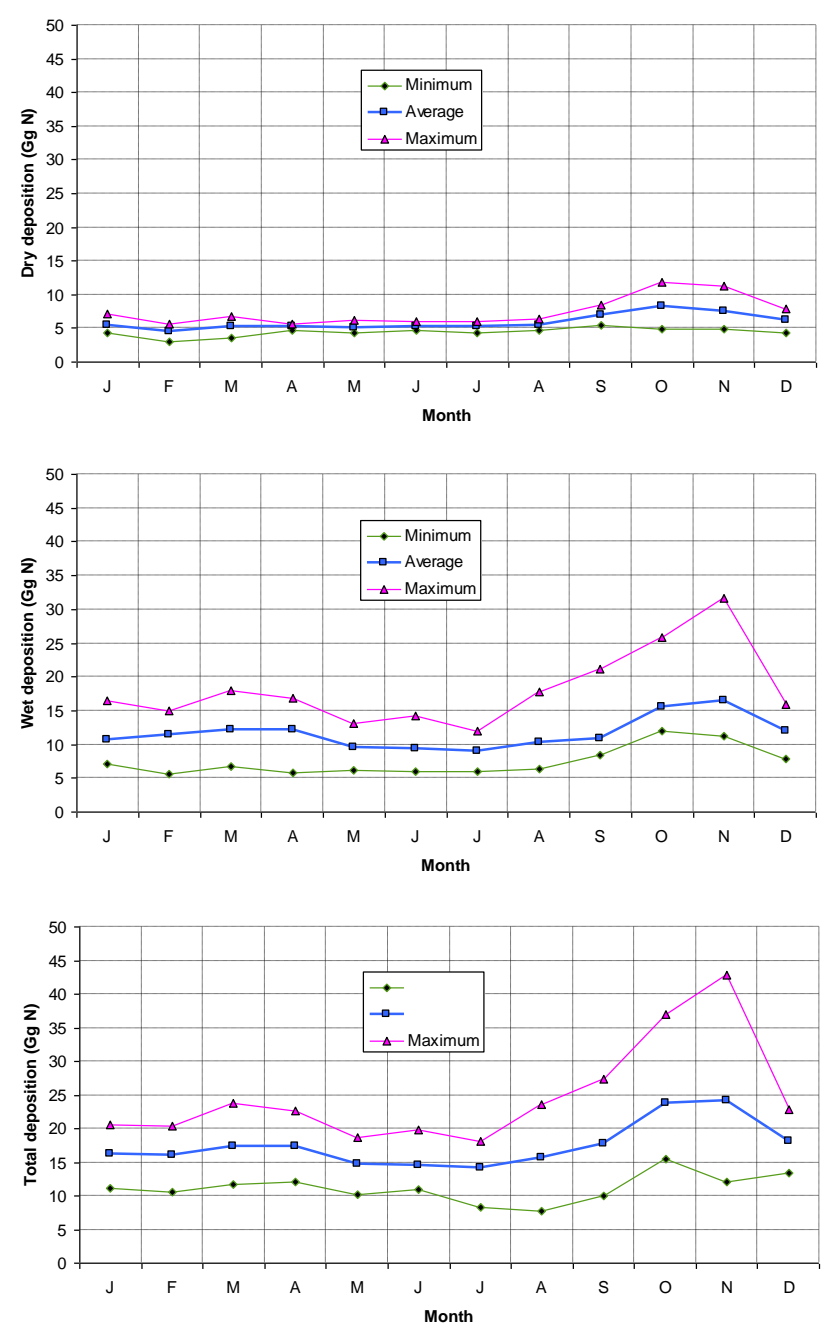

Fig. 11. Monthly minimum, maximum and monthly average (over $12 \mathrm{yr}$ ) deposition of dry, wet and total nitrogen to the Baltic Sea basin in the period 1995-2006.

and monthly reduced wet deposition are very similar and relatively well correlated with correlation coefficient equal to 0.65 . The minima of monthly deposition in the considered period are similar, slightly above $1 \mathrm{Gg} \mathrm{N}$, however they occur in different years. The maxima of monthly oxidised wet $(16.9 \mathrm{Gg} \mathrm{N})$ and reduced wet $(14.8 \mathrm{Gg})$ deposition occurred in the same month and year-October 2000. The maxima of monthly oxidised dry $(6.7 \mathrm{Gg} \mathrm{N})$ and reduced dry $(6.2 \mathrm{Gg} \mathrm{N})$ deposition also occur in the same month - October, but in different years: in 1995 for oxidised dry and in 2000 for reduced dry deposition.

Seasonal and monthly variability is much higher for wet deposition than for dry deposition (Fig. 10). This is the implication of large differences in monthly precipitation amounts in the considered period, but also the result of variations of concentrations in air and water. By contrast, dry deposition rates are not necessarily correlated with high concentrations, 


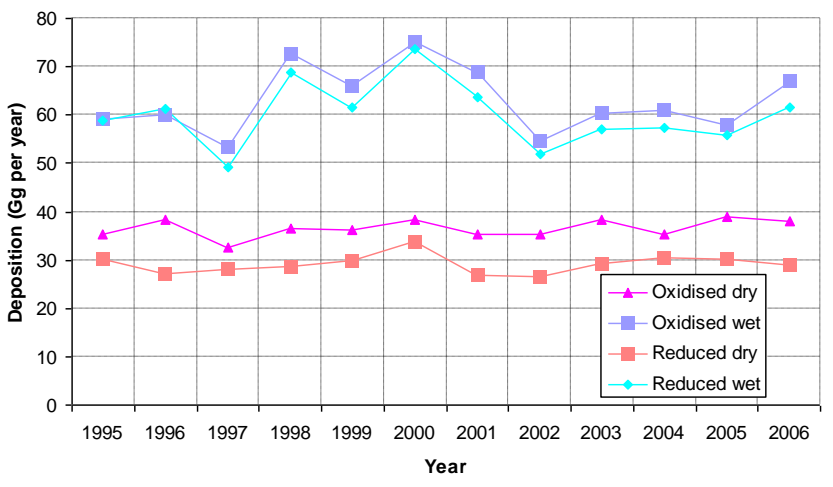

Fig. 12. Annual deposition to the Baltic Sea basin of oxidised dry, oxidised wet, reduced dry and reduced wet nitrogen in the period 1995-2006, calculated with constant emissions from 2006 and variable meteorology for all years.

because conditions related to high air concentrations (low wind speed, suppressed turbulence) do not favour large deposition velocities. Most of the maxima in Fig. 10 can be noticed for the autumn months, October and November, both for wet and dry deposition.

In order to detect the seasonal change of monthly dry, wet and total nitrogen deposition, we have calculated minimum, maximum and average value for each month of the period 1995-2006. The results are shown in Fig. 11. October and November are the months with the maximum of monthly dry, wet and total deposition, whereas summer months June and July are those with minimum of monthly wet and total deposition for the considered period. The minimum of monthly dry deposition occurs in February. The values of monthly wet and total deposition are also slightly higher in the spring months of March and April.

The correlation of wind speed and precipitation on a seasonal basis can be noticed in Fig. 11. For the autumn months October and November when the strong storms on the Baltic Sea are most frequent and surface wind speed reaches the seasonal maximum. For these two months, the highest values are visible in monthly dry, wet and total deposition.

\subsection{The effects of meteorological variability on the deposition}

Meteorological variability plays an important role in determining the transport distance and life time of the pollutants. A key question is to what extent different meteorological conditions influence the main characteristics of transport and pollutant exchange. In order to study the impact of meteorology in detail, we have made model simulations with constant emissions of 2006, but with varying meteorology for the years 1995-2006. Such an experiment gives more insight into the importance of meteorology in transporting pollutants and also into their atmospheric chemistry and removal rates from the atmosphere.
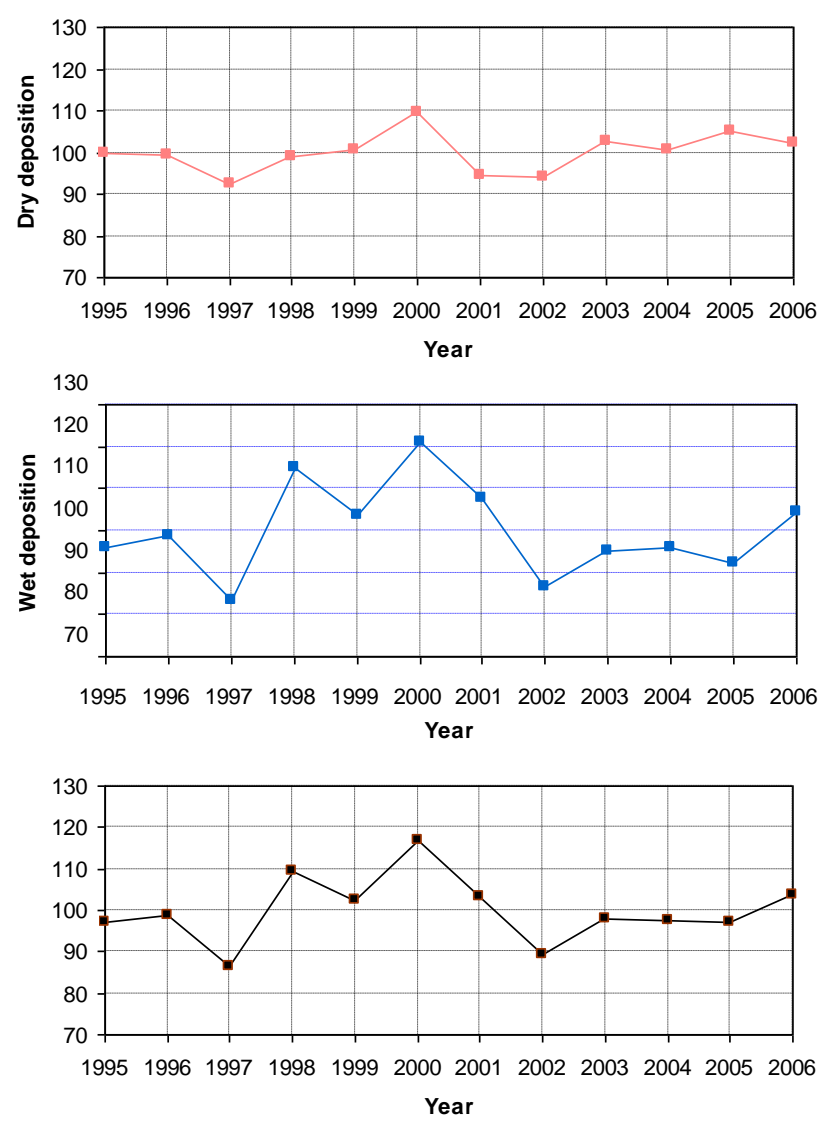

Fig. 13. Annual deposition of dry, wet and total nitrogen to the Baltic Sea basin for each year of the period 1995-2006 in \% of the average value over the entire period. Results of the model run with constant emissions from 2006 and variable meteorology.

Figure 12 shows the deposition of oxidised dry, oxidised wet, reduced dry and reduced wet nitrogen into the Baltic Sea for the period 1995-2006, resulting from the scenario runs we made. The results presented in Fig. 12 - with constant emissions are similar to those presented in Fig. 7 - with variable emissions, indicating again a significant role of meteorological conditions in variability of computed wet deposition of nitrogen. A large inter-annual variability can be seen in oxidised wet and reduced wet deposition, whereas, interannual variability in oxidised dry and reduced dry deposition remains relatively low. There is a good correlation between annual wet deposition to the Baltic Sea basin and annual average precipitation over the Baltic Sea basin, indicating that precipitation is the main meteorological parameter influencing the deposition. There is also slightly lower, but still good correlation between annual total deposition and annual precipitation. However, precipitation alone cannot entirely explain the variability in the deposition. For example, a clear maximum of all kinds of deposition, for the considered period, occurs in 2000, whereas, annual precipitation for this year $(662 \mathrm{~mm})$ is only the third highest and much lower than 
Table 3. Top ten contributors to annual oxidised, reduced and total nitrogen deposition to the Baltic Sea basin averaged over the period 1997-2006. Units: Gg N per year. Source codes: DE - Germany, PL - Poland, DK - Denmark, GB - United Kingdom, SE - Sweden, BAS - international ship traffic on the Baltic Sea, FR - France, RU - Russian Federation, NOS - international ship traffic on the North Sea, FI Finland, NL - The Netherlands.

\begin{tabular}{ccccccccc}
\hline \multirow{2}{*}{ Rank } & \multicolumn{2}{c}{ Oxidised N } & & \multicolumn{2}{c}{ Reduced N } & & \multicolumn{2}{c}{ Total N } \\
\cline { 2 - 3 } \cline { 7 - 8 } \cline { 7 - 8 } & Source & Deposition & & Source & Deposition & & Source & Deposition \\
\hline 1 & DE & 17.38 & & DE & 23.31 & & DE & 40.69 \\
2 & GB & 11.91 & & DK & 16.36 & & PL & 24.70 \\
3 & PL & 11.24 & & PL & 13.46 & & DK & 20.18 \\
4 & BAS & 10.95 & & SE & 8.38 & & GB & 14.48 \\
5 & NOS & 7.11 & & FR & 3.85 & & SE & 12.82 \\
6 & RU & 5.49 & & FI & 3.15 & & BAS & 9.42 \\
7 & FR & 5.29 & & NL & 3.13 & & FR & 9.15 \\
8 & SE & 4.44 & & UA & 3.04 & & RU & 8.02 \\
9 & DK & 3.83 & & GB & 2.57 & & NOS & 6.82 \\
10 & FI & 3.65 & & RU & 2.53 & & FI & 6.80 \\
\hline
\end{tabular}

the maximum of precipitation in the year 1998 (791 mm). In this case, other than precipitation, meteorological factors like annual patterns of wind direction, mixing height and temperature play an important role in the deposition. A relatively large contribution of Germany to total nitrogen deposition into the Baltic Sea basin in the year 1999 and 2000 suggests that the atmospheric transport from the regions with high nitrogen emissions can be also responsible for the deposition maximum in the same year.

The time series of relative deposition of dry, wet and total nitrogen to the Baltic Sea basin is shown in Fig. 13 for the period 1995-2006 and model run with 2006 emissions and variable meteorology. The relative deposition is presented in $\%$ of the average value for the entire period. The range of inter-annual variability in total deposition is significantly changing from $87 \%$ to $117 \%$ of the average value. There is more variability in wet deposition, with the range $83-121 \%$ of average than in dry deposition with the range $92-110 \%$ of average. However minimum and maximum of both wet and dry deposition occurs in the same years, 1997 and 2000, respectively, resulting in clear minimum and maximum of the total deposition in the same years. The influence of variable meteorological conditions is especially visible for the period 1997-2002. The difference between maximum and minimum of annual total deposition is $30 \%$ and caused mainly by large differences in wet nitrogen deposition. The interannual variability estimated with the EMEP Unified model is much higher than the one calculated with the MATCH model 5.1-8\% (Langner et al. 2009). However, these calculations have been performed for different periods and this can be the reason.

The coefficient of variation of nitrogen deposition, from the model run with constant 2006 emissions, has been calculated for each grid square of the Baltic Sea basin and expressed in \% of average deposition for the period 1995-2006.
The results for total deposition are shown in Fig. 14. The ranges of the coefficient of variation in the Baltic Sea basin for oxidised dry, oxidised wet, reduced dry and reduced wet deposition are 3-19\%, 6-23\%, 3-23\% and 7-30\%, respectively. The coefficient of variation of total nitrogen deposition is in similar range $4-21 \%$. The range of the coefficient of variation for precipitation is also similar, but the minimum value is higher compared to deposition: $11-23 \%$.

\section{Source allocation of nitrogen deposition}

Air concentrations and wet deposition of nitrogen compounds in the Baltic Sea region can be estimated both from measurements and from the model calculations. However, the information about the main emission sources contributing to nitrogen deposition into the Baltic Sea basin can be obtained only from the results of the model run. Therefore, the calculation of source-receptor relationships is one of the most important tasks for the EMEP Unified model.

The source allocation budget for the Baltic Sea basin has been calculated for the 10-yr period: 1997-2006, following the needs of the Baltic Sea Action Plan (HELCOM, 2010). The results of these calculations as a list of top ten contributors to annual oxidised, reduced and total nitrogen deposition to the Baltic Sea basin, averaged over the period 1997-2006 are shown in Table 3.

Germany is the number one contributor to all kinds of nitrogen deposition, followed by Poland and Denmark among the HELCOM Contracting Parties. A significant role of long range transport and distant sources in contribution to oxidised nitrogen deposition is marked by United Kingdom in the second position followed by North Sea ship traffic and France. Over the 1997-2006 period, the average contributions by Germany, the United Kingdom and Poland to oxidised nitrogen deposition into the Baltic Sea basin were 


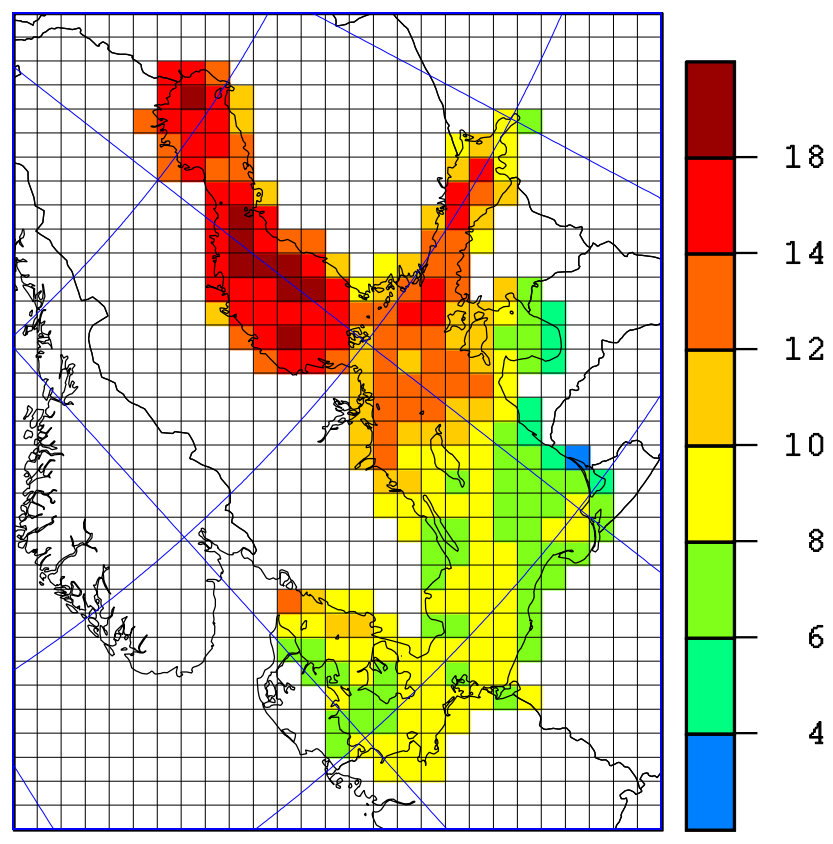

Fig. 14. Map of coefficient of variation (over the period 1995-2006) of total nitrogen deposition to the Baltic Sea basin. Deposition is calculated with constant emissions from 2006 and variable meteorology for all years. Coefficient of variation is expressed in \% of average deposition for each model grid square.

$16 \%, 11 \%$ and $10 \%$, respectively. The joint emissions from HELCOM Contracting parties and ship emissions from the Baltic Sea contribute $54 \%$ to oxidised nitrogen deposition.

The role of distant sources is not so large, but also visible in case of reduced nitrogen deposition, with France being the fifth largest contributor with $4 \%$ of the total reduced nitrogen deposition. Germany is again the largest contributor with the whole $24 \%$ followed by Denmark (17\%) and Poland (14\%). The sum of all sources from the HELCOM Contracting Parties, contribute $64 \%$ to reduced nitrogen deposition.

The contribution of Germany to total nitrogen deposition $(20 \%)$ is almost twice as high as number two on the list Poland (12\%) and number three Denmark (10\%). There is also a substantial contribution, $7 \%$, of one distant source United Kingdom to total annual average nitrogen deposition to the Baltic Sea basin. The contribution of all sources from HELCOM Contracting Parties and ship emissions from the Baltic Sea to total nitrogen deposition is $54 \%$.

The contribution of main sources to annual nitrogen deposition for each year of the period 1997-2006 is relatively stable (Fig. 15). Germany dominates the picture with 14$17 \%, 22-29 \%$ and $18-22 \%$ contribution to oxidised, reduced and total nitrogen, respectively. There is a tendency of slightly increasing German contribution with time, especially for reduced nitrogen deposition from $14 \%$ in 1997 to $29 \%$ in 2006. There is also a systematic increase of contribution to oxidised nitrogen deposition from the international a)

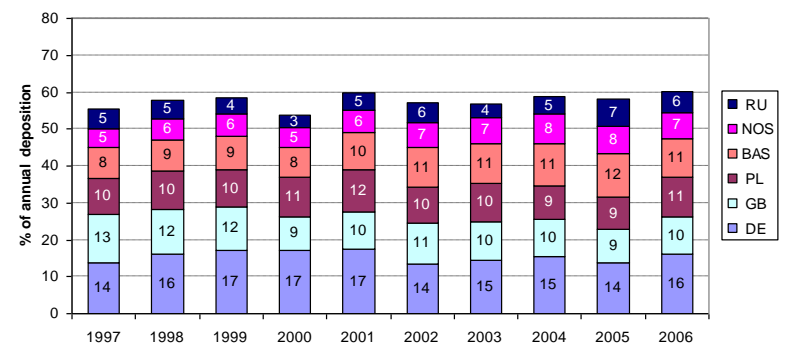

b)

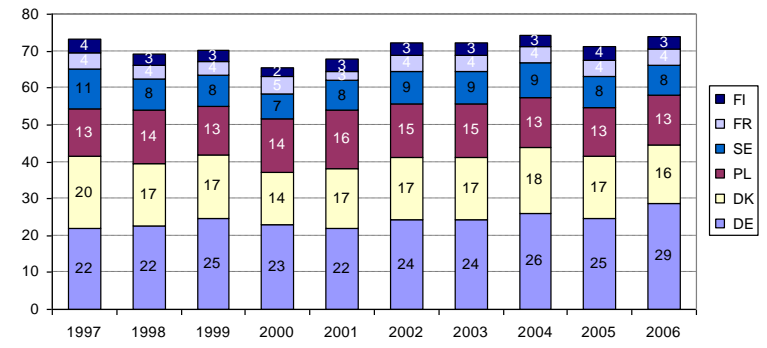

c)

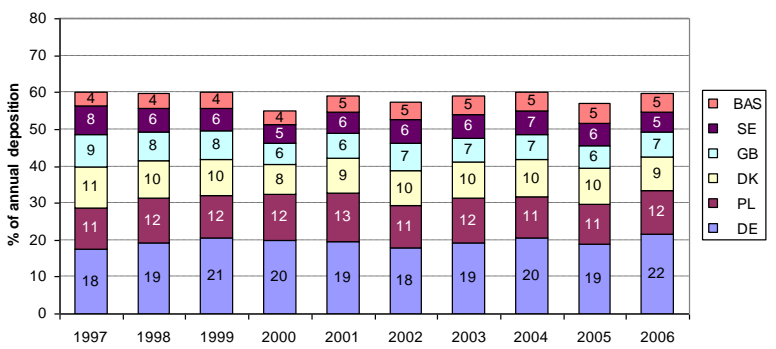

Fig. 15. Time series of main contributions to annual deposition of nitrogen into the Baltic Sea basin in the period 1997-2006. Contributions are in \% of: (a) oxidised, (b) reduced and (c) total deposition. Source codes: DE - Germany, DK - Denmark, FI - Finland, FR - France, GB - United Kingdom, PL - Poland, RU - Russia, SE - Sweden, BAS - international ship traffic on the Baltic Sea, NOS - international ship traffic on the North Sea.

ship traffic on the Baltic Sea from $8 \%$ in 1997 to $11 \%$ in 2006. The second major contributor - Poland remains on similar level for all kind of the deposition. On the other hand, a certain decrease can be observed in the contributions from Denmark, Sweden and a distant source - United Kingdom. These reductions reflect, to a large extent, the reductions in nitrogen oxides and ammonia emissions, in the above mentioned sources, in the period 1997-2006.

\section{Conclusions}

The aim of this study was the estimation of atmospheric nitrogen deposition to the Baltic Sea basin and identification of main emission sources contributing to the deposition. The same version (rv3.1) of the EMEP Unified model and consistent meteorological and emission data have been used for calculating nitrogen deposition and source allocation budget. 
Atmospheric nitrogen deposition into the Baltic Sea basin has been calculated for the period of 12 yr: 1995-2006. The level of annual total nitrogen deposition into the Baltic Sea basin has changed from $230 \mathrm{Gg} \mathrm{N}$ in 1995 to $199 \mathrm{Gg} \mathrm{N}$ in 2006, decreasing $13 \%$. This value corresponds well with the total nitrogen emission reduction (11\%) in the HELCOM Contracting Parties. Wet deposition was higher than dry deposition (63-70\% of total deposition) and oxidised deposition was slightly higher than reduced deposition (51-54\% of total). A clear south-north gradient can be noticed in calculated deposition fields of oxidised and reduced nitrogen (Fig. 6), reflecting similar gradients in the emission fields of nitrogen oxides and ammonia (Fig. 3). This similarity is also common for other years of the considered 12-yr period.

The calculated monthly nitrogen deposition for each month of the 1995-2006 period remain on similar level for most of the months during the year. Two exceptions are October and November when maxima of monthly deposition can be noticed for the considered period.

In general, the changes in nitrogen deposition in the considered period follow the changes in nitrogen emissions, especially in the HELCOM Contracting Parties. However, inter-annual variation in annual deposition in the period 1995-2006 is large (79-108\% of 1995 value) compared to variation of annual nitrogen emissions (87-100\% of 1995 value). This fact can be explained by large inter-annual changes in meteorological conditions and especially in precipitation (86-127\% of 1995 value). Analysis of annual nitrogen emissions and deposition in the period 1995-2006 shows that in order to evaluate and see the effects of nitrogen emission reduction, it is necessary to use a longer period than one or two years. Figure 9 indicates that the evaluation period should not be shorter than five years.

The model run with constant emissions from the year 2006 and variable meteorology in the period 1995-2005 shows that the differences between maximum and minimum deposition of oxidised wet and reduced wet nitrogen are large, $35 \%$ and $45 \%$ respectively, of the average value for the entire period. The differences between maximum and minimum deposition of oxidised dry and reduced dry nitrogen are much lower $17 \%$ and $24 \%$, respectively. These results confirm again that large inter-annual variability in computed nitrogen deposition is mainly caused by variable meteorological conditions and precipitation first of all.

The distribution of standard deviation of total nitrogen deposition over the Baltic Sea basin has been used as a measure of inter-annual variability. A clear south-north gradient can be noticed in this distribution with minima located in the south, where the maxima of average deposition can be found and maxima of the standard deviation in the Northern part of the Baltic Sea basin close to minima of the average deposition. In the places where the deposition is low the influence of the transport pattern is much higher than in the places with relatively high levels of the deposition.
The results presented here suggest that in order to improve accuracy of computed deposition and source allocation budget, not only accurate emission inventories are necessary, but meteorological data of good quality as well.

Germany is the number one contributor for all kinds of nitrogen deposition, followed by Poland and Denmark among the HELCOM Contracting Parties. A significant role of long range transport and distant sources in contribution to oxidised nitrogen deposition is marked by United Kingdom in the second position and by presence of North Sea ship traffic and France on the list. The average, over the period 19972006 contribution of Germany, Poland and Denmark to total nitrogen deposition into the Baltic Sea basin is $20 \%, 12 \%$ and $10 \%$, respectively. The contribution of main sources to annual nitrogen deposition is relatively stable. Contribution of Germany is within the range $18-22 \%$ with slightly increasing tendency. There is also a systematic increase of contribution from the international ship traffic on the Baltic Sea from 4\% in 1997 to $5 \%$ in 2006. Contribution from Poland remains on, more or less, the same level mostly between 11 and $12 \%$ and range of contribution from Denmark is $8-11 \%$.

Acknowledgements. We thank our colleagues David Simpson, Ágnes Nyíri and Anna Benedictow from the EMEP Centre-West for discussions and help with emission and meteorological data necessary for the model runs. Wenche Aas from the Norwegian Institute for Air Research and Birthe Marie Steensen from the EMEP Centre-West helped us with measurement data necessary for comparison of model results with observations. We are also indebted to the referees for all corrections, comments and valuable suggestions improving the final version of the paper. A large part of the work presented here was supported by the HELCOM Convention. Finally, we acknowledge the financial support by the European Commission (NitroEurope-IP, project 017841), and by the EMEP project under UNECE.

Edited by: M. Sutton

\section{References}

Bartnicki, J., Gusev, A., Aas, W. and Valiyaveetil, S.: Atmospheric Supply of Nitrogen, Lead, Cadmium, Mercury and Dioxines/Furanes to the Baltic Sea in 2010, EMEP Centres Joint Report for HELCOM, EEMEP/MSC-W TECHNICAL REPORT 2/2008, Norwegian Meteorological Institute, Oslo, Norway, 2010.

Benedictow, A.: Documentation and verification of the 1999 PARLAM-PS meteorological fields used as input for Eulerian EMEP model, Technical report, Norwegian Meteorological Institute, Oslo, Norway, Research Note no. 111, 2003.

Berge H., Gauss M., and Hjellbrekke, A.-G.: EMEP Unified model performance for acidifying and eutrophying components and photo-oxidants in 2008, Supplementary material to EMEP Status Report 1/2010, Norwegian Meteorological Institute, Oslo, Norway, 2010. 
Bjørge, D. and Skålin, R.: PARLAM - the parallel HIRLAM version at DNMI, Norwegian Meteorological Institute, Oslo, Norway, Research Report No. 27, ISSN 0332-9879, 1995.

CEIP Webpage, available online at: http://www.ceip.at/, last access: 10 December 2010.

EMEP Webpage, available online at: http://www.emep.int/, last access: 10 December 2010.

Fagerli, H. and Aas, W.: Trends of nitrogen in air and precipitation: Model results and observations at EMEP sites in Europe, 19802003, Environ. Pollut., 154(3), 448-461, 2008.

Fagerli, H., Gauss, M., Benedictow, A., Griesfeller, J., Jonson, J. E., Nyíri, Á., Schultz, M., Simpson, D., Stensen, B. E., Tsyro, S., Valdebenito, Á., Wind, P., Aas, W., Hjellbrekke, A-G., Mareckova, K., Wankmüller, R., Iversen, T., Kirkevåg, A., Seland, $\varnothing$ and Vieno, M.: Transboundary acidification, eutrophication and ground level ozone in Europe in 2009, EMEP Status Report 1/2011, Norwegian Meteorological Institute. Oslo, Norway, 2011.

HELCOM: Airborne nitrogen loads to the Baltic Sea. Helsinki Commission, Baltic Marine Environment Commission, HELCOM Environmental Focal Point Information, 1-7, 2005a.

HELCOM: Atmospheric supply of nitrogen, lead, cadmium, mercury and lindane to the Baltic Sea over the period 1996-2000, Balt. Sea Environ. Proc., No. 101, 1-75, 2005 b.

HELCOM. Eutrophication in the Baltic Sea - An integrated thematic assessment of the effects of nutrient enrichment and eutrophication in the Baltic Sea region. Balt. Sea Environ. Proc., 115B, 1-152, 2009.

HELCOM Webpage, available online at: http://www.helcom.fi/, last access: 10 December 2010.

Hertel O., Ambelas Skjøth C., Brandt J., Christensen, J. H., Frohn, L. M., and Frydendall, J.. Operational mapping of atmospheric nitrogen deposition to the Baltic Sea, Atmos. Chem. Phys., 3, 2083-2099, doi:10.5194/acp-3-2083-2003, 2003.

Langner, J., Andersson, C., and Engardt, M.: Atmospheric input of nitrogen to the Baltic Sea basin: present situation, variability due to meteorology and impact of climate change, Boreal Env. Res., 14, 226-237, 2009.
Rolff, C., Elmgren, R., and Voss, M.: Deposition of nitrogen and phosphorus on the Baltic Sea: seasonal patterns and nitrogen isotope composition, Biogeosciences, 5, 1657-1667, doi:10.5194/bg-5-1657-2008, 2008.

Semeena, V. S., Nyíri, Á., Valdebenito, A., Simpson, D., and Fagerli, H.: Trends in source allocation of pollutants, Transboundary acidification, eutrophication and ground level ozone in Europe in 2007, EMEP Status Report 1/2009, Norwegian Meteorological Institute, Oslo, Norway, 47-63, 2009.

Simpson, D., Fagerli, H., Hellsten, S., Knulst, J. C., and Westling, O.: Comparison of modelled and monitored deposition fluxes of sulphur and nitrogen to ICP-forest sites in Europe, Biogeosciences, 3, 337-355, doi:10.5194/bg-3-337-2006, 2006 a.

Simpson, D., Butterbach-Bahl, K., Fagerli, H., Kesik, M., Skiba, U., and Tang, S.: Deposition and emissions of reactive nitrogen over European forests: A modelling study, Atmos. Environ., 40, 5712-5726, 2006b.

Undén, P., Rontu, L., Järvinen, H., Lynch, P., Calvo, J., Cats, G., Cuaxart, J., Eerola, K., Fortelius, C., Garcia-Moya, J.A., Jones, C., Lenderlink, G., Mc-Donald, A., McGrath, R., Navascues, B., Nielsen, N.W., Ødegaard, V., Rodriguez,E., Rummukainen, M., Rööm, R., Sattler, K., Sass, B.H., Savijärvi, H., Schreur, B. W., Sigg, R., The, H., and Tijm, A.: HIRLAM-5 Scientific Documentation, HIRLAM-5 Project. Available from SMHI, 601767 Norrköping, Sweden, 2002.

Vestreng, V.: Inventory review. Emission data reported to CLRTAP. MSC-W Status Report 2003, EMEP/MSC-W Note 1/2003, Norwegian Meteorological Institute, Oslo, Norway, 2003.

Wulff, F., Humborg, Ch., Medina, M. R., Mörth, M., Savchuk, O.. and Sokolov, A.: Revision of the country allocation of nutrient reductions in the Baltic Sea Action Plan - Section A: Hydrological adjusted riverine load and atmospheric loads from different countries averaged for 2000-2006. Technical Report No. 1. Baltic Nest Institute, Stockholm University, Sweden, 2009. 